\title{
Suppression of the Wnt signaling pathway may contribute to the inhibition of proliferation of human hepatocellular carcinoma SMMC-7721 cells by esculetin
}

\author{
XINFENG FAN ${ }^{1}$, HAIYUAN DU ${ }^{2}$, YAOGUI SUN ${ }^{1}$, JUNBING JIANG ${ }^{1}$, \\ ZHIRUI WANG $^{3}$, WEI YIN ${ }^{1}$, KUOHAI FAN ${ }^{1}$ and HONGQUAN LI ${ }^{1}$ \\ ${ }^{1}$ College of Animal Science and Veterinary Medicine, Shanxi Agricultural University, Taigu, Shanxi 030801; ${ }^{2}$ College of \\ Traditional Chinese Medicine, Beijing University of Chinese Medicine, Beijing 100000, P.R. China; ${ }^{3}$ Transplantation \\ Biology Research Center, Massachusetts General Hospital and Harvard Medical School, Boston, MA 02115, USA
}

Received March 18, 2016; Accepted April 7, 2017

DOI: $10.3892 / \mathrm{ol} .2017 .6364$

\begin{abstract}
The aims of the present study were to investigate the effects of esculetin on the proliferation of human hepatocellular carcinoma SMMC-7721 cells and to determine the underlying mechanism behind this activity. An MTT assay was used to assess cell proliferation, reverse transcription-quantitative polymerase chain reaction was used to determine the relative mRNA expression levels of $\beta$-catenin, c-Myc and cyclin D1, and western blot analysis was utilized to determine the levels of the associated proteins. Compared with the dimethyl sulfoxide control, esculetin reduced the cell viability of SMMC-7721 and HL-7702 cells in a dose- and time-dependent manner. Treatment of SMMC-7721 cells with esculetin resulted in downregulation of the mRNA and protein levels of $\beta$-catenin, c-Myc and cyclin D1. Esculetin increased the phosphorylation of $\beta$-catenin at Ser33/Ser37/Thr41 and inhibited the proliferation of human hepatoma SMMC-7721 cells by suppressing the Wnt signaling pathway. The results of the present study suggest that esculetin inhibited the Wnt/ $\beta$-catenin signaling pathway in SMMC-7721 cells and may have potential as an effective anti-cancer drug, acting to inhibit the Wnt/ $\beta$-catenin signaling pathway.
\end{abstract}

\section{Introduction}

Hepatocellular carcinoma (HCC) is one of the most common malignant tumors, with a mortality rate of $\sim 1$ million people per year worldwide (1-4). However, the precise molecular mechanism of HCC tumorigenesis remains largely unknown.

Correspondence to: Dr Hongquan Li, College of Animal Science and Veterinary Medicine, Shanxi Agricultural University, 1 Ming-Xian South Road, Taigu, Shanxi 030801, P.R. China E-mail: livets@163.com

Key words: esculetin, Wnt signaling pathway, $\beta$-catenin, $\beta$-catenin phosphorylation
Potentially curative therapies include surgical resection, transplantation and percutaneous ablation, but are not suitable for all patients. Surgery is effective for early-stage HCC and the postoperative recurrence rate is low; however, in a large number of patients, $\mathrm{HCC}$ is identified at an advanced disease stage, and thus are not suitable for surgical intervention. Chemotherapy is an alternative option for these patients, but development of resistance limits the success of these approaches (5). Thus, the development of potent and effective therapeutic modalities for the treatment of HCC, particularly late-stage HCC, is urgently required.

It has been well established that the aberrant activation of signaling pathways controlling normal cellular proliferation (including epidermal growth factor and RAS/mitogen-activated protein kinase pathways), survival (including the AKT/mechanistic target of rapamycin pathway), differentiation (including the Wnt and hedgehog pathways) and angiogenesis (including the vascular endothelial growth factor and platelet-derived growth factor pathways) are heterogeneously dysregulated in the majority of solid tumors (6). The dependence of cancer cells on gain-of-function mutations to oncogenes and loss-of-function mutations to tumor suppressor genes has led to the development of successful targeted molecular therapies. In 2008, sorafenib, a small molecule inhibitor of multiple tyrosine kinases, was approved for the clinical treatment of several cancer types. Sorafenib significantly prolongs median overall survival, resulting in a $44 \%$ improvement in the survival of HCC patients compared with placebo (7). Targeted molecular therapy is an emerging field for the treatment of various types of cancer, with numerous agents targeting different cancer-associated signaling molecules currently undergoing preclinical and clinical trials.

The Wnt signaling pathway has been investigated intensively due to its pivotal role in regulating the expression of numerous genes that are critical for cell proliferation and differentiation. The Wnt signaling pathway is perturbed in a number of diseases, including cancer, and diseases of the bone and cardiovascular system (8). The Wnt pathway is upregulated in $>30 \%$ of HCCs $(9,10)$, suggesting that targeting Wnt signaling is a promising strategy for the treatment of HCC. 
Qin Pi is a traditional Chinese medicine and a common natural antioxidant. Qin Pi contains several pharmacologically active ingredients, including esculetin, that have in vivo anti-inflammatory and peripheral analgesic activity (11). Esculetin has been reported to suppress oxidative damage to cellular DNA induced by lipid hydroperoxide (12). Notably, esculetin has been demonstrated to suppress the proliferation of human colon cancer cells by directly targeting $\beta$-catenin (13). Kim et al (14) reported that esculetin induced the death of human colon cancer cells via the reactive oxygen species-mediated mitochondrial apoptosis pathway. In addition, Wang et al (15) reported that esculetin induces apoptosis in HCC cells by initiating a mitochondrial-dependent apoptosis pathway. However, whether esculetin inhibits the growth and proliferation of HCC via the Wnt signaling pathway remains to be determined.

In the present study, the effects of esculetin on the growth and proliferation of human HCC SMMC-7721 cells were investigated and the activity of the Wnt signaling pathway was assessed following esculetin treatment.

\section{Materials and methods}

Chemicals and reagents. RPMI-1640, fetal bovine serum, and trypsin were purchased from Hyclone (GE Healthcare, Logan, UT, USA). Penicillin, streptomycin, and trypsin were purchased from Gibco (Thermo Fisher Scientific, Inc., Waltham MA, USA). Sodium dodecylsulfate, Ponceau S, dithiothreitol, phenylmethylsulfonyl fluoride and bovine serum albumin were purchased from Sigma-Aldrich (Merck KGaA, Darmstadt, Germany). The polymerase chain reaction (PCR) kit and the SYBR-Green Quantitative RT-PCR kit were purchased from Takara Biotechnology Co., Ltd. (Dalian, China). Anti- $\beta$-catenin (cat. no. 8480; dilution 1:1,000), anti-cyclin D1 (cat. no. AB20509a; dilution 1:1,000), anti-c-Myc (cat. no. BS2462; dilution 1:1,000), anti- $\beta$-actin (cat. no. bs-0061R; dilution 1:1,000), anti-phospho- $\beta$-catenin (Ser33/Ser37/Thr41) (cat. no. 9561; dilution 1:1,000) and horseradish peroxidase-conjugated goat anti-rabbit (cat. no. BA1054; dilution 1:10,000) antibodies were obtained from Cell Signaling Technology, Inc. (Danvers, MA, USA).

Esculetin was obtained from the Food and Drug Verification Research Institute in China (batch number, 110741-200506; Beijing, China). Esculetin was dissolved in dimethyl sulfoxide (DMSO) to obtain a stock solution with a concentration of $0.8 \mathrm{M}$, which was stored at $4^{\circ} \mathrm{C}$. Cells were treated with esculetin at a final concentration of 50, 100, 200, 300,400 or $500 \mu \mathrm{mol} / 1$.

Cell culture and treatment. Human HCC SMMC-7721 cells were obtained from the American Type Culture Collection (Manassas, VA, USA). Normal liver HL-7702 cells were obtained from Obio Technology Co., Ltd. (Shanghai, China). The cells were maintained in RPMI-1640 medium supplemented with $10 \%$ heat-inactivated fetal bovine serum and $1 \%$ penicillin-streptomycin at $37^{\circ} \mathrm{C}$ in a $5 \% \mathrm{CO}_{2}$ incubator. Cells were treated with vehicle (0.5\% DMSO) alone, or 50, 100, 200, 300,400 or $500 \mu \mathrm{mol} / 1$ esculetin for 24,48 and $72 \mathrm{~h}$.

Cell viability assay. Cell viability was determined using an MTT assay. SMMC-7721 cells and HL-7702 cells were seeded at a density of $1 \times 10^{5}$ cells/well in 96-well plates. After incubation for $\sim 24 \mathrm{~h}$ at $37^{\circ} \mathrm{C}$ in a $5 \% \mathrm{CO}_{2}$ incubator, the cells were treated with the aforementioned concentrations of esculetin. The MTT assay was performed after 24, 48 and $72 \mathrm{~h}$ of treatment. The culture medium was discarded, $30 \mu 10.5 \%$ (w/v) MTT dissolved in 1X PBS was added to each well and the plate was incubated for $3 \mathrm{~h}$ at $37^{\circ} \mathrm{C}$. After incubation for $3 \mathrm{~h}$, the culture medium was discarded and $120 \mu \mathrm{l}$ DMSO was added into each well. Following incubation for $30 \mathrm{~min}$ and slow shaking for $15 \mathrm{~min}$ at $37^{\circ} \mathrm{C}$, the absorbance at $490 \mathrm{~nm}$ was measured with a microplate reader. The experiment was repeated in triplicate. Cell viability was expressed as a percentage of proliferation against the control (untreated cells), which was set at $100 \%$.

Total RNA isolation and reverse transcription-quantitative PCR (RT-qPCR) analysis. SMMC-7721 cells were cultured in 6-well plates. Following treatment with 100 or $300 \mu \mathrm{mol} / 1$ esculetin or DMSO for 24,48 and $72 \mathrm{~h}$, the total RNA was extracted using TRIzol (Gibco; Thermo Fisher Scientific, Inc.), according to the manufacturer's instructions. The RNA concentration was determined using a Nanodrop 8000 spectrophotometer (Thermo Fisher Scientific, Wilmington, DE, USA), and the integrity of RNA was visualized on a $1 \%$ agarose gel using a gel documentation system (Universal Hood II; Bio-Rad Laboratories, Inc., Hercules, CA, USA). qPCR was performed in a $20-\mu 1$ reaction mixture using SYBR-Green Quantitative RT-PCR kit and one-step PCR.

The sequences of the primers were designed using Primer Premier 5.0 (Premier Biosoft, Palo Alto, CA, USA) and are in Table I. The PCR procedure was as follows: Pre-denaturation at $95^{\circ} \mathrm{C}$ for $30 \mathrm{sec}$, denaturation at $95^{\circ} \mathrm{C}$ for $5 \mathrm{sec}$, annealing at $60^{\circ} \mathrm{C}$ for $30 \mathrm{sec}$, and extension at $72^{\circ} \mathrm{C}$ for $15 \mathrm{sec}$. The PCR was performed for 40 cycles, followed by a final extension at $72^{\circ} \mathrm{C}$ for $10 \mathrm{~min}$. The threshold cycle $\left(\mathrm{C}_{\mathrm{q}}\right)$ correlates inversely with the target mRNA level, and the relative quantitation of the relative gene expression levels was calculated using the $2^{-\Delta \Delta \mathrm{Cq}}$ method (16).

Western blot analysis. Total protein was extracted from cells using radioimmunoprecipitation assay lysis buffer containing $1 \%$ protease inhibitor cocktail (Roche Applied Science, Penzberg, Germany). Equal amounts of protein extracts $(50 \mu \mathrm{g})$ were separated using 10\% SDS-PAGE and subsequently transferred onto a polyvinylidene difluoride membrane. Membranes were blocked with $5 \%(\mathrm{w} / \mathrm{v})$ skimmed milk dissolved in Tris-buffered saline plus Tween-20 [TBS-T; 0.1\% Tween-20; ( $\mathrm{pH} 8.3)]$ at room temperature for $1 \mathrm{~h}$. The membranes were then incubated overnight at $4^{\circ} \mathrm{C}$ with primary antibodies (all 1:1,000 dilution). Following washing with Tween-20 [TBS-T; $0.1 \%$ Tween-20 ( $\mathrm{pH} \mathrm{8.3)],} \mathrm{the} \mathrm{membranes} \mathrm{were} \mathrm{incubated} \mathrm{with}$ horseradish peroxidase-labeled secondary antibodies for $60 \mathrm{~min}$ at room temperature. The immunoreactive bands were visualized using an enhanced chemiluminescence kit (GE Healthcare Life Sciences). $\beta$-actin was used as a loading control.

Statistical analysis. GraphPad Prism 5.02 (GraphPad Software, Inc., La Jolla, CA, USA) and Microsoft Excel (Microsoft Corporation, Redmond, WA, USA) were used for statistical analysis. Statistical analysis of data for multiple 
Table I. Sequences of primers for reverse transcription-polymerase chain reaction.

\begin{tabular}{llc}
\hline Gene & \multicolumn{1}{c}{ Sense $\left(5^{\prime}-3^{\prime}\right)$} & Antisense $\left(5^{\prime}-3^{\prime}\right)$ \\
\hline$\beta$-catenin & CCAAGTGGGTGGTATAGAGG & AGTCCATAGTGAAGGCGAAC \\
c-Myc & TTGTTGCGGAAACGACG & TCATAGGTGATTGCTCAGGAC \\
cyclin D1 & GCATGTTCGTGGCCTCTAAG & TTCAATGAAATCGTGCGGGG \\
GAPDH & ACCAAATTGCCAGAGTGACC & CAAAGCAGCATCTCATCCAA
\end{tabular}

c-Myc, Myc proto-oncogene.

groups was performed using one-way analysis of variance and Dunnett's test. All experiments were performed at least three times. $\mathrm{P}<0.05$ was considered to indicate a statistically significant difference.

\section{Results}

Esculetin dose- and time-dependently inhibits the proliferation of SMMC-7721 and HL-7702 cells. To test the cytotoxicity of esculetin, SMMC-7721 cells and normal liver HL-7702 cells were treated with different concentrations of esculetin $(50,100,200,300,400$ or $500 \mu \mathrm{mol} / \mathrm{l})$ for 24,48 and $72 \mathrm{~h}$, and the cell viability was assessed using an MTT assay. Compared with the $0.5 \%$ DMSO control, esculetin inhibited the proliferation of SMMC-7721 and HL-7702 cells in a doseand time-dependent manner (Fig. 1). A pre-experiment was carried out to define the experiment density of DMSO, and it was found that $0.5 \%$ DMSO has no effect on SMMC-7721 or HL-7702 cells.

Esculetin dose-and time-dependently damages the cell morphological structure of SMMC-7721 and HL-7702 cells. To assess whether esculetin damages the cell morphological structure, SMMC-7721 cells were treated with 100 or $300 \mu \mathrm{mol} / 1$ esculetin for $72 \mathrm{~h}$ and the cell morphology was assessed under a microscope. Compared with the blank and DMSO-treated control cells, SMMC-7721 cells treated with esculetin exhibited reduced adherence to the bottom of the bottle and poor refraction (as indicated by the arrows in Fig. 2). The degree of change was more evident at the higher esculetin concentration $(300 \mu \mathrm{mol} / \mathrm{l})$. Together, these results demonstrate that esculetin inhibited the proliferation of SMMC-7721 cells in a dose-dependent manner.

Esculetin downregulates the $m R N A$ and protein levels of $\beta$-catenin, $c$-Myc and cyclin D1. In order to assess whether esculetin affects the activity of the Wnt/ $\beta$-catenin signaling pathway, SMMC-7721 cells were treated with different concentrations of esculetin (100 or $300 \mu \mathrm{mol} / 1)$ for 24,48 and $72 \mathrm{~h}$. The mRNA and protein levels of $\beta$-catenin and its downstream targets c-Myc and cyclin D1 were measured using RT-qPCR and immunoblotting. Esculetin at either 100 or $300 \mu \mathrm{mol} / 1$, for 48 and $72 \mathrm{~h}$, significantly reduced the mRNA level of $\beta$-catenin, with a stronger effect at $300 \mu \mathrm{mol} / 1$ ( $\mathrm{P}<0.05$; Fig. 3A). Furthermore, treatment of cells with $300 \mu \mathrm{mol} / 1$ esculetin for $24 \mathrm{~h}$ resulted in a significant reduction in the mRNA levels of c-Myc (P<0.05; Fig. 3B) and cyclin D1 (P<0.05; Fig. 3C), which
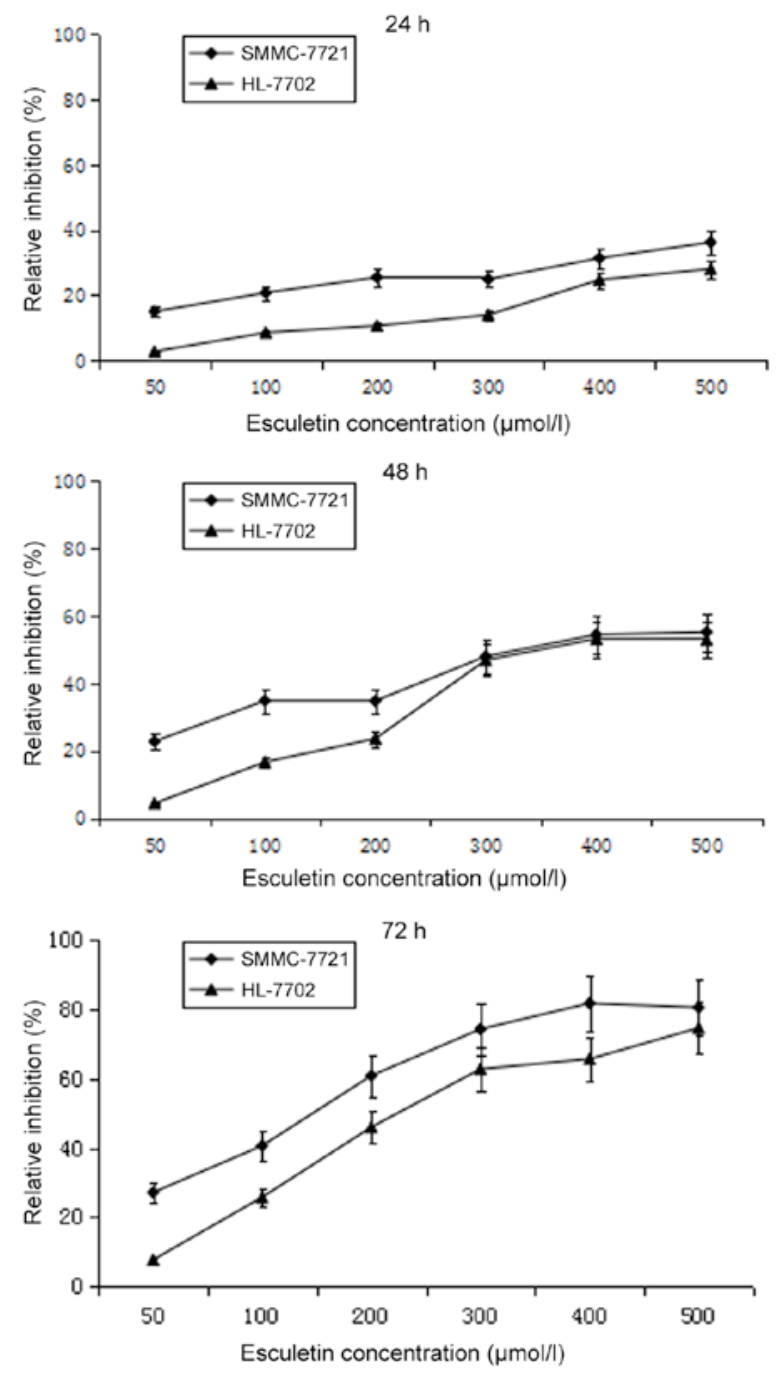

Figure 1. Esculetin inhibits the proliferation and alters the morphological structure of SMMC-7721 cells. SMMC-7721 or HL-7702 cells were seeded at a density of $1 \times 10^{5}$ cells/well in 96-well plates. After incubation for $24 \mathrm{~h}$ at $37^{\circ} \mathrm{C}$ in a $5 \% \mathrm{CO}_{2}$ incubator, cells were treated with $50,100,200,300,400$, or $500 \mu \mathrm{mol} / 1$ esculetin. The MTT assay was performed after incubation for 24,48 , and $72 \mathrm{~h}$. Data are shown relative to dimethyl sulfoxide $(0.5 \%)$, the control treatment. Each value represents the mean \pm standard deviation of three independent experiments.

were further enhanced following treatment for 48 and $72 \mathrm{~h}$. Treatment of cells with $100 \mu \mathrm{mol} / 1$ esculetin for 48 and $72 \mathrm{~h}$ also resulted in a significant reduction in the level of c-Myc $(\mathrm{P}<0.05$; Fig. 3B) and cyclin D1 $(\mathrm{P}<0.05$; Fig. 3C) mRNA, with a stronger reduction following treatment for $72 \mathrm{~h}$. Similar to the 


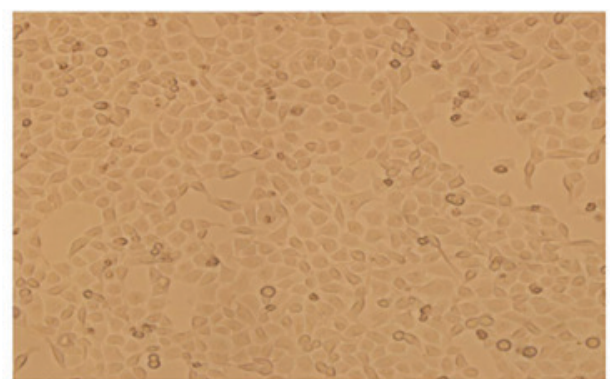

$A(x 200)$

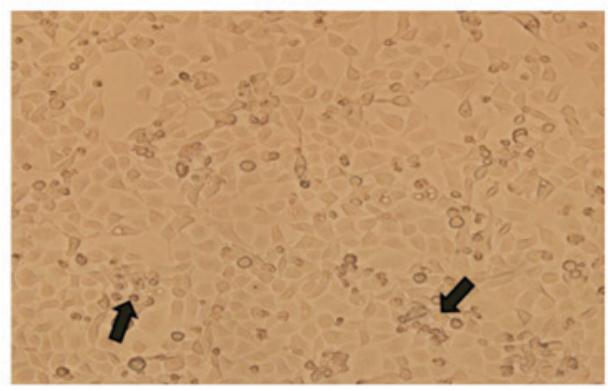

$C(\times 200)$

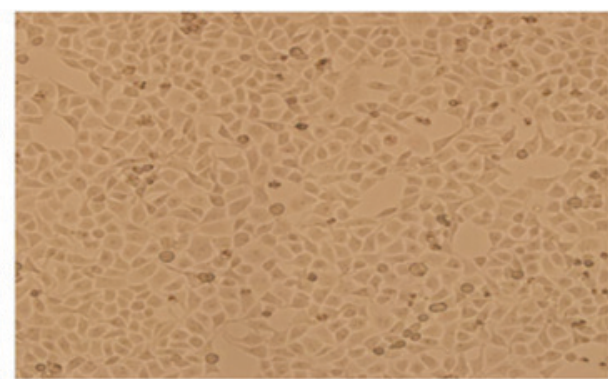

B (x200)

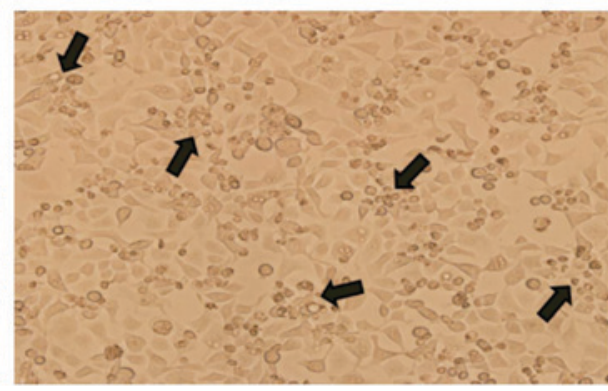

D (x200)

Figure 2. The morphology of SMMC-7721 cells was observed by light microscopy (x200 magnification). Following treatment with different concentrations of esculetin for $72 \mathrm{~h}$, SMMC-7721 cells were observed under a microscope. (A) Blank control; (B) 0.3\% DMSO; (C) $100 \mu \mathrm{mol} / 1 \mathrm{esculetin}$; (D) $300 \mu \mathrm{mol} / 1$ esculetin.

A

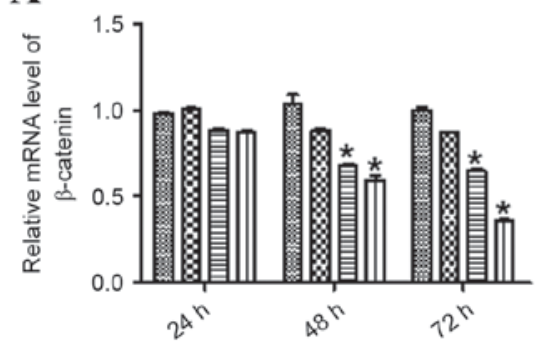

C
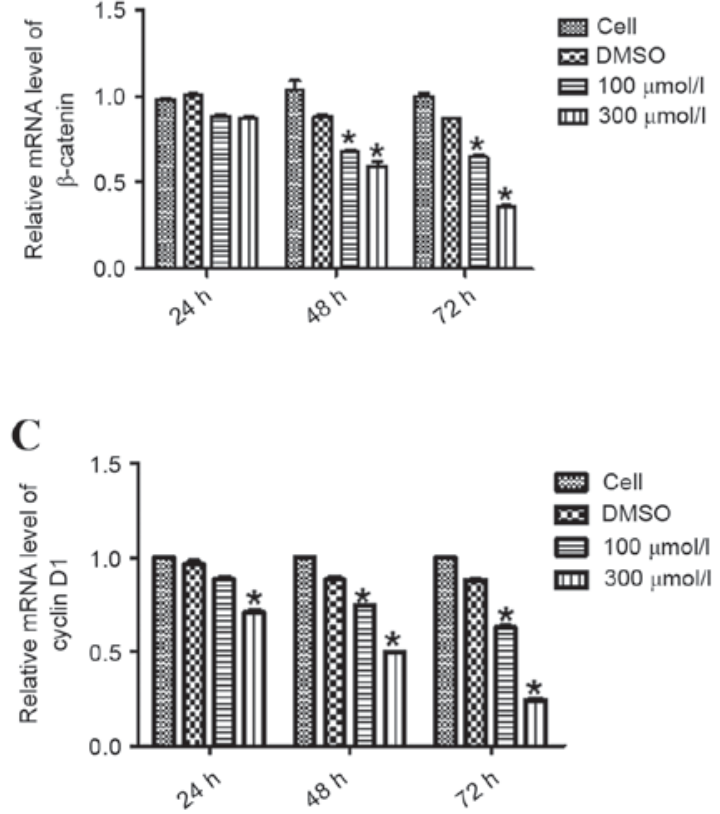

B

D

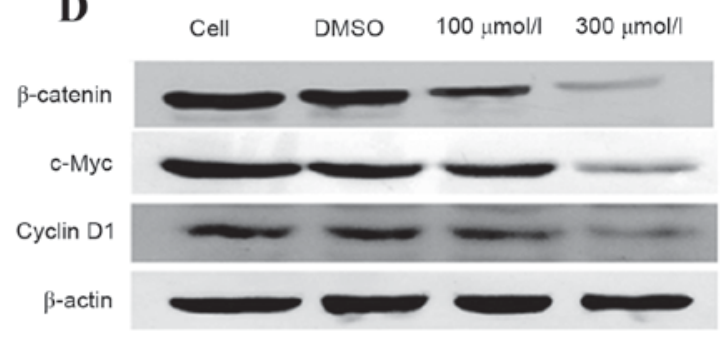

Figure 3. Esculetin suppresses the activation of Wnt/ $\beta$-catenin signaling in SMMC-7721 cells. SMMC-7721 cells were treated with the indicated concentration of esculetin for 24, 48, and $72 \mathrm{~h}$. Total RNA was extracted for reverse transcription-quantitative polymerase chain reaction analysis to determine the mRNA levels of $\beta$-catenin (A), c-Myc (B), and cyclin D1 (C), with $\beta$-actin serving as an internal control. Each value represents the mean \pm standard deviation of three experiments. (D) SMMC-7721 cells were treated for $72 \mathrm{~h}$ with the indicated concentration of esculetin, with DMSO vehicle for or not treated. Total protein was extracted for western blot analysis of $\beta$-catenin, c-Myc, and cyclin D1, with $\beta$-actin as the loading control. "P<0.05 vs. DMSO. DMSO, dimethyl sulfoxide; c-Myc, Myc proto-oncogene.

alteration of mRNA levels, esculetin downregulated the protein levels of $\beta$-catenin and its downstream targets, c-Myc and cyclin D1, in a dose-dependent manner (Fig. 3D). These results indicate that esculetin inhibited the $\mathrm{Wnt} / \beta$-catenin signaling pathway in SMMC-7721 cells.
Esculetin induces the phosphorylation of $\beta$-catenin. In order to investigate the mechanism by which esculetin inhibits the Wnt signaling pathway, SMMC-7721 cells were treated with 100 or $300 \mu \mathrm{mol} / 1$ esculetin for $24 \mathrm{~h}$ and the phosphorylation level of $\beta$-catenin was determined by immunoblotting. The results 


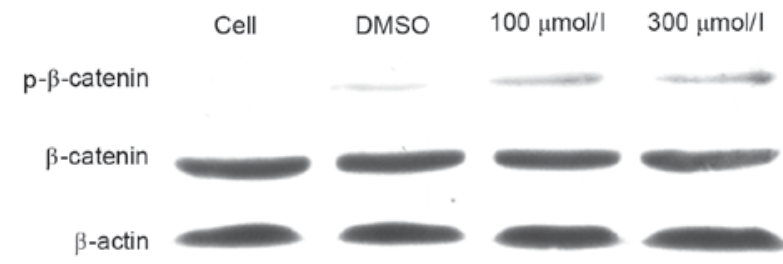

Figure 4. Esculetin induces the phosphorylation of $\beta$-catenin. SMMC-7721 cells were treated with 100 or $300 \mu \mathrm{mol} / 1$ esculetin or dimethyl sulfoxide vehicle for $24 \mathrm{~h}$. Total protein was extracted for western blot analysis of $\beta$-catenin and $\mathrm{p}-\beta$-catenin (Ser33/Ser37/Thr41), with $\beta$-actin as a loading control. p- $\beta$-catenin, phosphorylated $\beta$-catenin.

revealed that the total $\beta$-catenin protein level was not evidently decreased following 100 or $300 \mu \mathrm{mol} / 1$ esculetin treatment for $24 \mathrm{~h}$. However, the phospho- $\beta$-catenin level (Ser33/Ser37/Thr41) was evidently increased following 100 or $300 \mu \mathrm{mol} / 1$ esculetin treatment for $24 \mathrm{~h}$ (Fig. 4). Since it has been established that phosphorylation of $\beta$-catenin (Ser33/Ser37/Thr41) leads to degradation of the cytoplasmic $\beta$-catenin (17), $\beta$-catenin cannot accumulate in the nucleus and will not activate the transcription of downstream target genes of the $\mathrm{Wnt} / \beta$-catenin signaling pathways so will not promote cancer cell growth, proliferation and metastasis (18). These results suggest that esculetin promotes the phosphorylation of $\beta$-catenin, thereby leading to suppression of Wnt/ $\beta$-catenin signaling in SMMC-7721 cells.

\section{Discussion}

In the present study, esculetin was demonstrated to inhibit the proliferation of SMMC-7721 and HL-7702 cells in a dose- and time-dependent manner. Furthermore, treatment of SMMC-7721 cells with esculetin resulted in cell shrinkage, membrane blebbing and vacuolization in the cytoplasm. Esculetin downregulated the mRNA and protein expression levels of $\beta$-catenin, and its downstream targets c-Myc and cyclin D1. Notably, treatment of SMMC-7721 cells with esculetin resulted in the phosphorylation of $\beta$-catenin. The present results suggest that esculetin inhibits the viability of SMMC-7721 by enhancing the phosphorylation of $\beta$-catenin (Ser33/Ser37/Thr41) to inhibit Wnt signaling pathway.

The Wnt signaling pathway serves a key role in normal embryonic development and the central nervous system; in addition, it regulates cell growth, migration and differentiation. Evidence suggests that the Wnt signaling pathway is frequently dysregulated in the majority of cancer types (19); therefore, blocking the Wnt signaling pathway is a promising strategy for cancer treatment. $\beta$-catenin is a key component of the Wnt signaling pathway; cytoplasmic $\beta$-catenin is normally maintained at a low level by proteasomal degradation. The binding of Wnt proteins to Frizzled receptors results in the accumulation of unphosphorylated $\beta$-catenin, which translocates into the nucleus and activates the expression of Wnt target genes, including c-Myc and cyclin D1 (19-21). c-Myc is the most commonly overexpressed oncogene in human cancer and is mutated in $20 \%$ of human cancers (22). Cyclin D1 is a key regulator of the $\mathrm{G} 1$ to $\mathrm{S}$ phase transition in the normal cell cycle, and the excess expression of cyclin D1 is observed in numerous types of human cancer, including those of the lymphatic system, breast, esophagus, lung and bladder (23-27).
c-Myc and cyclin D1 are target genes of the Wnt signaling pathway and contribute to regulation of cell cycle progression by Wnt signaling. In the present study, esculetin reduced the mRNA and protein levels of c-Myc and cyclin D1, suggesting that one of the mechanisms by which esculetin inhibits the proliferation of SMMC-7721 cells is through suppression of c-Myc and cyclin D1 expression.

Unphosphorylated $\beta$-catenin avoids proteasomal degradation and subsequently translocates into the nucleus. A high concentration of nuclear $\beta$-catenin is associated with a poor prognosis in certain cancer types. It has been reported that cytoplasmic $\beta$-catenin can be degraded though phosphorylation at Ser33, Ser37, and Thr41 (28). Accumulating evidence indicates that numerous natural products can inhibit the activity of Wnt signaling. Haraguchi et al (29) reported that Ajuba can effectively reduce $\beta$-catenin expression in human cervical cancer cells by inducing the phosphorylation of $\beta$-catenin via glycogen synthase kinase (GSK)-3 $\beta$. In addition, Feng et al (30) reported that sulindac reduced the phosphorylation level of GSK-3 $\beta$, thereby increasing the phosphorylation levels of $\beta$-catenin. To confirm that the increased phosphorylation levels of $\beta$-catenin (at Ser33/Ser37/Thr41) were not due to alteration of total $\beta$-catenin levels, total $\beta$-catenin levels following treatment with esculetin for $24 \mathrm{~h}$ was observed. Results showed that treatment of cells with esculetin for $24 \mathrm{~h}$ did not alter the amount of $\beta$-catenin protein, but markedly increased the phosphorylation of $\beta$-catenin (at Ser33/Ser37/Thr41) in a concentration-dependent manner. As a result, we hypothesized that esculetin enhanced the phosphorylation of $\beta$-catenin (at Ser33/Ser37/Thr41), thereby leading to its degradation. Subsequantly, we hypothesized that esculetin inhibits transcriptional activity of $\beta$-catenin by inducing $\beta$-catenin degradation. Although the mechanism by which the phosphorylation of $\beta$-catenin is induced by esculetin remains to be determined, the findings of the present study suggest that inhibition of Wnt signaling is an important mechanism for natural products to prevent tumorigenesis and inhibit the proliferation of cancer cells.

In conclusion, the present study found that esculetin inhibited the Wnt signaling pathway in SMMC-7721 cells, which was accompanied by increased phosphorylation of total $\beta$-catenin. The results of the present study suggest that one of the molecular mechanisms of the antitumor effects of esculetin may be through inhibition of the Wnt signaling pathway.

\section{Acknowledgements}

This study was supported by a grant from the Agricultural Science and Technology Achievements Transformation Project (no. 2014GB2A300003).

\section{References}

1. Parkin DM, Bray F, Ferlay J and Pisani P: Global cancer statistics, 2002. CA Cancer J Clin 55: 74-108, 2005.

2. El-Serag HB and Mason AC: Rising incidence of hepatocellular carcinoma in the United States. N Engl J Med 340: 745-750, 1999.

3. Sherman M: Hepatocellular carcinoma: Epidemiology, risk factors, and screening. Semin Liver Dis 25: 143-154, 2005.

4. Rossi L, Zoratto F, Papa A, Iodice F, Minozzi M, Frati L and Tomao S: Current approach in the treatment of hepatocellular carcinoma. World J Gastrointest Oncol 2: 348-359, 2010. 
5. Johnson PJ: Hepatocellular carcinoma: Is current therapy really altering outcome? Gut 51: 459-462, 2002.

6. Hoshida Y, Toffanin S, Lachenmayer A, Villanueva A, Minguez B and Llovet JM: Molecular classification and novel targets in hepatocellular carcinoma: Recent advancements. Semin Liver Dis 30: 35-51, 2010.

7. Llovet JM, Ricci S, Mazzaferro V, Hilgard P, Gane E, Blanc JF, de Oliveira AC, Santoro A, Raoul JL, Forner A, et al: Sorafenib in advanced hepatocellular carcinoma. N Engl J Med 359: 378-390, 2008.

8. Takahashi-Yanaga $\mathrm{F}$ and Sasaguri T: The Wnt/beta-catenin signaling pathway as a target in drug discovery. J Pharmaco Sci 104: 293-302, 2007.

9. Chiang DY, Villanueva A, Hoshida Y, Peix J, Newell P, Minguez B, LeBlanc AC, Donovan DJ, Thung SN, Solé M, et al: Focal gains of VEGFA and molecular classification of hepatocellular carcinoma. Cancer Res 68: 6779-6788, 2008.

10. Boyault $\mathrm{S}$, Rickman DS, de Reyniès A, Balabaud C, Rebouissou S, Jeannot E, Hérault A, Saric J, Belghiti J, Franco D, et al: Transcriptome classification of HCC is related to gene alterations and to new therapeutic targets. Hepatology 45: 42-52, 2007.

11. Tubaro A, Del Negro P, Ragazzi E, Zampiron S and Della Loggia R: Anti-inflammatory and peripheral analgesic activity of esculetin in vivo. Pharmacol Res Commun 20 (Suppl 5): S83-S85, 1988

12. Kaneko T, Tahara S and Takabayashi F: Suppression of lipid hydroperoxide-induced oxidative damage to cellular DNA by esculetin. Biol Pharm Bull 26: 840-844, 2003.

13. Lee SY, Lim TG, Chen H, Jung SK, Lee HJ, Lee MH, Kim DJ, Shin A, Lee KW, Bode AM, et al: Esculetin suppresses proliferation of human colon cancer cells by directly targeting beta-catenin. Cancer Prev Res (Phila) 6: 1356-1364, 2013.

14. Kim AD, Han X, Piao MJ, Hewage SR, Hyun CL, Cho SJ and Hyun JW: Esculetin induces death of human colon cancer cells via the reactive oxygen species-mediated mitochondrial apoptosis pathway. Environ Toxicol Pharmacol 39: 982-989, 2015.

15. Wang J, Lu ML, Dai HL, Zhang SP, Wang HX and Wei N: Esculetin, a coumarin derivative, exerts in vitro and in vivo antiproliferative activity against hepatocellular carcinoma by initiating a mitochondrial-dependent apoptosis pathway. Braz J Med Biol Res 48: 245-253, 2015.

16. Livak KJ and Schmittgen TD: Analysis of relative gene expression data using real-time quantitative PCR and the 2(-Delta Delta C(T)) method. Methods 25: 402-408, 2001
17. Rubinfeld B, Albert I, Porfiri E, Fiol C, Munemitsu S and Polakis P: Binding of GSK3beta to the APC-beta-catenin complex and regulation of complex assembly. Science 272. 1023-1026, 1996

18. Lee HH, Uen YH, Tian YF, Sun CS, Sheu MJ, Kuo HT, Koay LB, Lin CY, Tzeng CC, Cheng CJ, et al: Wnt-1 protein as a prognostic biomarker for hepatitis b-related and hepatitis C-related hepatocellular carcinoma after surgery. Cancer Epidemiol Biomarkers Prev 18: 1562-1569, 2009

19. Takahashi-Yanaga $F$ and Kahn M: Targeting Wnt signaling: Can we safely eradicate cancer stem cells? Clin Cancer Res 16: 3153-3162, 2010.

20. Clevers H: Wnt/beta-catenin signaling in development and disease. Cell 127: 469-480, 2006.

21. Moon RT, Kohn AD, De Ferrari GV and Kaykas A: WNT and beta-catenin signalling: Diseases and therapies. Nat Rev Genet 5: 691-701, 2004.

22. Nesbit CE, Tersak JM and Prochownik EV: MYC oncogenes and human neoplastic disease. Oncogene 18: 3004-3016, 1999.

23. Diehl JA: Cycling to cancer with cyclin D1. Cancer Biol Ther 1: 226-231, 2002.

24. Sherr CJ: Cancer cell cycles. Science 274: 1672-1677, 1996.

25. Landis MW, Pawlyk BS, Li T, Sicinski P and Hinds PW: Cyclin D1-dependent kinase activity in murine development and mammary tumorigenesis. Cancer Cell 9: 13-22, 2006.

26. Lee YM and Sicinski P: Targeting cyclins and cyclin-dependent kinases in cancer: Lessons from mice, hopes for therapeutic applications in human. Cell Cycle 5: 2110-2114, 2006.

27. Li Z, Wang C, Prendergast GC and Pestell RG: Cyclin D1 functions in cell migration. Cell Cycle 5: 2440-2442, 2006.

28. Moon RT: Wnt/beta-catenin pathway. Sci STKE 2005: cm1, 2005

29. Haraguchi K, Ohsugi M, Abe Y, Semba K, Akiyama T and Yamamoto T: Ajuba negatively regulates the Wnt signaling pathway by promoting GSK-3beta-mediated phosphorylation of beta-catenin. Oncogene 27: 274-284, 2008.

30. Feng XC, Wang XM, Zhang Y, Li J and Shen ZH: Sulindac induces SMMC-7721 cells apoptosis through inhibiting Wnt pathway. Fudan Univ J Med Sci: 522-526, 2007. 